\title{
Lung damage after long-term exposure of adult rats to sodium fluoride
}

\author{
Fayza Abdel-Raouf Abdel-Gawad, Maha Hussein Ashmawy, Sherif Mohamed Zaki, \\ Gaber Hassan Abdel-Fatah
}

Department of Anatomy, Faculty of Medicine, Cairo University, Cairo, Egypt

Submitted: 1 June 2012

Accepted: 9 September 2012

Arch Med Sci 2014; 10, 5: 1035-1040

DOI: 10.5114 /aoms.2014.46221

Copyright (c) 2014 Termedia \& Banach

\section{Abstract}

Introduction: Fluorides, when taken in amounts exceeding the standard therapeutic dosage, are regarded as toxic substances. Chronic fluorosis causes marked destruction of lung tissues. The study aimed to determine whether the effect of a chronic toxic dose of sodium fluoride on the lung of an adult male albino rat is reversible or irreversible. This was done through light and electron microscopic studies. Morphometric study was also done.

Material and methods: Forty adult male rats were used. The animals were divided into 3 groups: control group; group I (chronic fluorosis group) in which sodium fluoride was given daily for 3 months; and group II (recovery group) in which sodium fluoride was given daily for 3 months and after that the rats survived for another month.

Results: The lung of group I was characterized by presence of blood and lymph congestion. Thickening of alveolar septa was also observed with rupture of septa and widening of the air spaces. The area \% of collagen (1.13 \pm 0.5$)$, septal wall thickness $(13.47 \pm 6.1)$, and number of macrophages $(5 \pm 2.5)$ increased in comparison to the control group $(p \leq 0.05)$. With discontinuation of sodium fluoride (group II), no much improvement was observed.

Conclusions: Chronic fluorosis has many pathological effects on the lung which are irreversible.

Key words: chronic fluorosis, lung damage.
Corresponding author: Sherif Mohamed Zaki Anatomy Department Faculty of Medicine Cairo University El-Kasr Al Aini St Cairo, Egypt

Phone: +20226706317 $+201227457431$

E-mail: zaky.sherif@yahoo. com

\section{Introduction}

Fluorides, when taken in amounts exceeding the standard therapeutic dosage, are regarded as toxic substances [1]. Fluoride toxicity occurs due to high concentrations of fluoride in water sources or anthropogenic causes [2].

Chronic fluorosis can severely damage many systems of the human body [3]. Pathological effects on the central nervous system, skeletal musculature, stomach, liver, kidney, cardiovascular system, retina, and skin were reported [4]. Dental fluorosis can also occur during tooth formation [5]. Finally, lung and kidney damage is also well documented [6].

Kidney damage was observed in both proximal and distal tubules in the form of hydropic epithelial cell degeneration and moderate tubular dilatation. Shrunken glomeruli and vascular congestion were also observed [7]. 
Marked destruction of lung tissue in the form of loss of alveolar architecture, emphysematous areas, desquamation of alveolar epithelium and alveolar congestion was documented [8]. Hyperaemia, necrosis of epithelial cells, numerous macrophages in interalveolar septa, infiltrations in the area of blood vessels and emphysematous blebs were also reported [1].

Whether the effect of chronic fluorosis in a toxic dose on the lung is transient or permanent is an important and interesting point. So the aim of our study was to evaluate the effect of a chronic toxic dose of sodium fluoride on the lungs of adult male albino rats. This was done through light and electron microscopic studies. Morphometric study was also done using the image analyzer.

\section{Material and methods}

Forty adult male Sprague Dawley rats (Animal House, Faculty of Medicine, Cairo University), weighing 250-300 g, were used. Five animals were housed per cage, and the animals were acclimatized to standard laboratory conditions (12:12-hour light-dark cycle, temperature $20^{\circ} \mathrm{C}$, fed ad libitum and allowed free water supply). The animals were deprived of food but allowed free access to tap water for $24 \mathrm{~h}$ before the experiment. Only male rats were used in this study to exclude possible sex differences. The experiments were performed according to the Helsinki agreement on the guiding principles for research involving animals and human beings.

The animals were divided into the following groups. Control group: This group was subdivided into two subgroups; each one consisted of ten rats. Subgroup a: the rats were sacrificed after
3 months. Subgroup b: the rats were sacrificed after 4 months. Group I (chronic fluorosis group): this group consisted of 10 rats. Sodium fluoride was given daily for three months, then the rats were sacrificed. Group II (recovery group): this group consisted of 10 rats. Sodium fluoride was given daily for three months, then the rats survived for another month before being killed.

Sodium fluoride was supplied as powder (Cornell Lab). It was dissolved in distilled water and given in a dose of $2.5 \mathrm{mg} / \mathrm{rat} / 24 \mathrm{~h}$. This high dose was aimed at studying the toxic effect of sodium fluoride [1]. The animals were sacrificed by a high dose of ether, and then dissected and the lung was taken.

\section{Light microscopic study}

Parts of the lung were fixed in buffered formol saline, processed for paraffin sections of $5 \mu \mathrm{m}$ thickness and sections were stained with haematoxylin and eosin $(\mathrm{H}+\mathrm{E})$ and Masson's trichrome for histological study [9]. The sections were examined and photographed using a Canon digital camera, attached to an IBM computer system.

\section{Ultrastructural study}

The other parts of obtained specimens were cut into small pieces, fixed in $4 \%$ glutaraldehyde then washed in phosphate buffer and post fixed in $1 \%$ osmium tetraoxide. Fixation was followed by dehydration and embedding in epoxy resins. Ultrathin sections were stained with uranyl acetate and lead citrate [10]. Examination and photography of specimens were carried out at using a Jeom-1400 transmission electron microscope

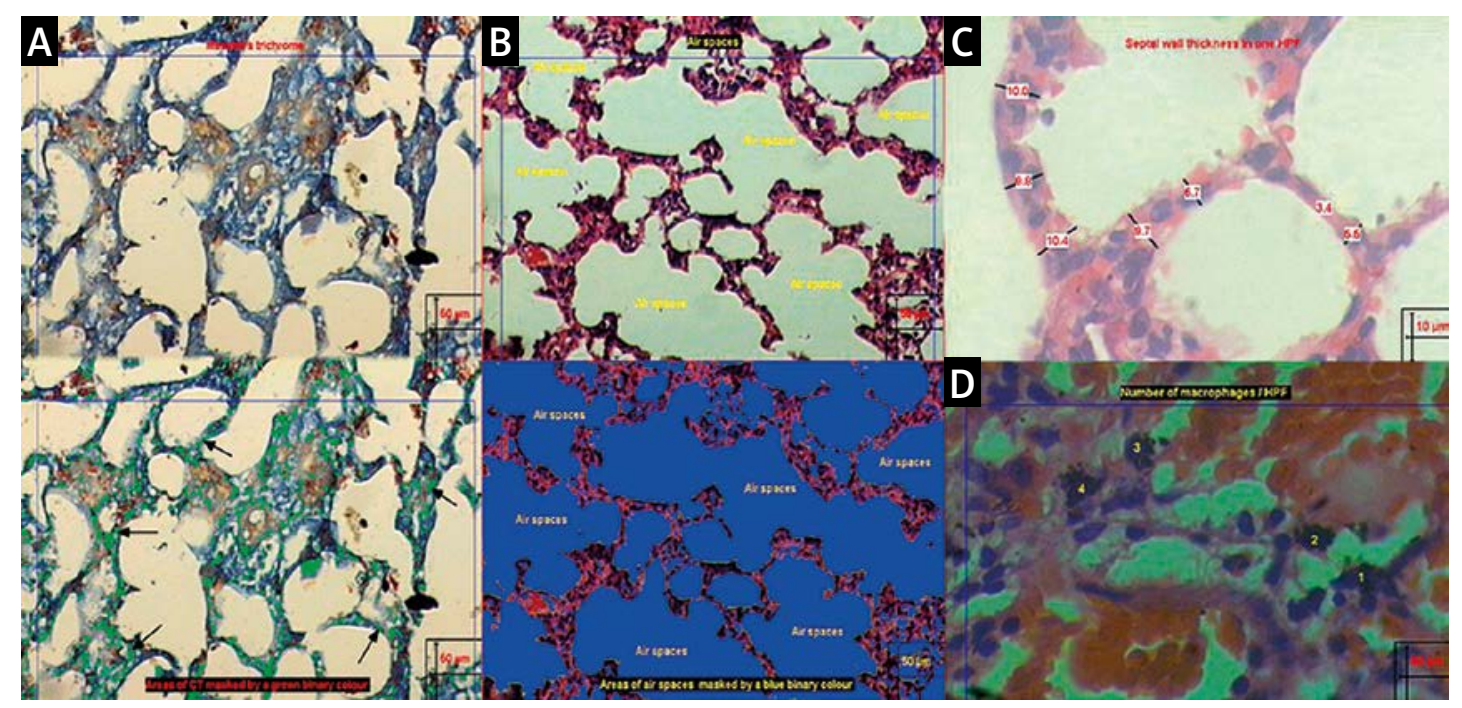

Figure 1. A - Areas of connective tissue in the upper half of the picture were masked by a green binary colour (arrows) in the lower half of the picture (Masson's trichrome 100x). B - Air spaces in the upper half of the picture were masked by a blue binary colour in the lower half of the picture $(H+E ; 100 x)$. C - Measurement of the septal wall thickness of the lung $(H+E ; 400 x)$. D - The way of counting macrophages $(H+E ; 400 x)$ 
(TEM) (Electron Microscopy Department, Faculty of Agriculture, Cairo University).

\section{Image analyzer study}

The sections were examined using Leica Qwin 500 image analysis software on an IBM operated computer system. Four specimen preparations from each rat (with a total of 40 preparations in each group) were subjected to quantitative studies. Ten readings were obtained in each specimen and the mean values were obtained (Figure 1).

The percentage area of collagen tissue fibres in Masson's trichrome stained sections was measured inside a standard measuring frame. The collagen tissue fibres were detected and masked by green binary colour. Then the area of the green binary colour was measured and expressed as percentage area in relation to the area of the standard measuring frame. The same previous steps were applied to the air spaces in $\mathrm{H}+\mathrm{E}$ stained sections. The septal wall thickness was measured using the interactive measuring menu. The number of macrophages was counted.

\section{Statistical analysis}

The data were collected and studied using the two-tailed ANOVA to compare between the different groups using the statistical program SPSS 20. The quantitative data were examined by Kolmogorov Smirnov test for normality. Significance was considered at $p$-value $<0.05$.

\section{Results}

\section{Results of $\mathrm{H}+\mathrm{E}$ stained sections}

Histological examination of the lung of the control rats exhibited normal architecture.

The lung of the chronic fluorosis group (group I) was characterized by the presence of blood and lymph congestion complicated finally with blood extravasation. Thickening of alveolar septa was observed in certain specimens and ruptured septa with widening of the air spaces were observed in others. Cellular infiltration was also a constant finding in this group. Not much improvement was observed in the recovery group (group II) compared to the chronic fluorosis group (Figure 2).

\section{Results of Masson's trichrome stained sections}

Thickening of the connective tissue was observed in group I in comparison to the control group. This finding regressed obviously in group II (Figure 3).

\section{Results of electron microscopy study}

The lumen of the bronchioles in group I was collapsed with disrupted cilia. The cytoplasm was attenuated and the mitochondria were swollen. Myelin figures were observed. Margination of the nuclei with irregularity of the nuclear membranes was also observed. Not much difference was observed in group II compared to group I apart from some mitotic figures in pneumocyte cell type II (Figure 4).

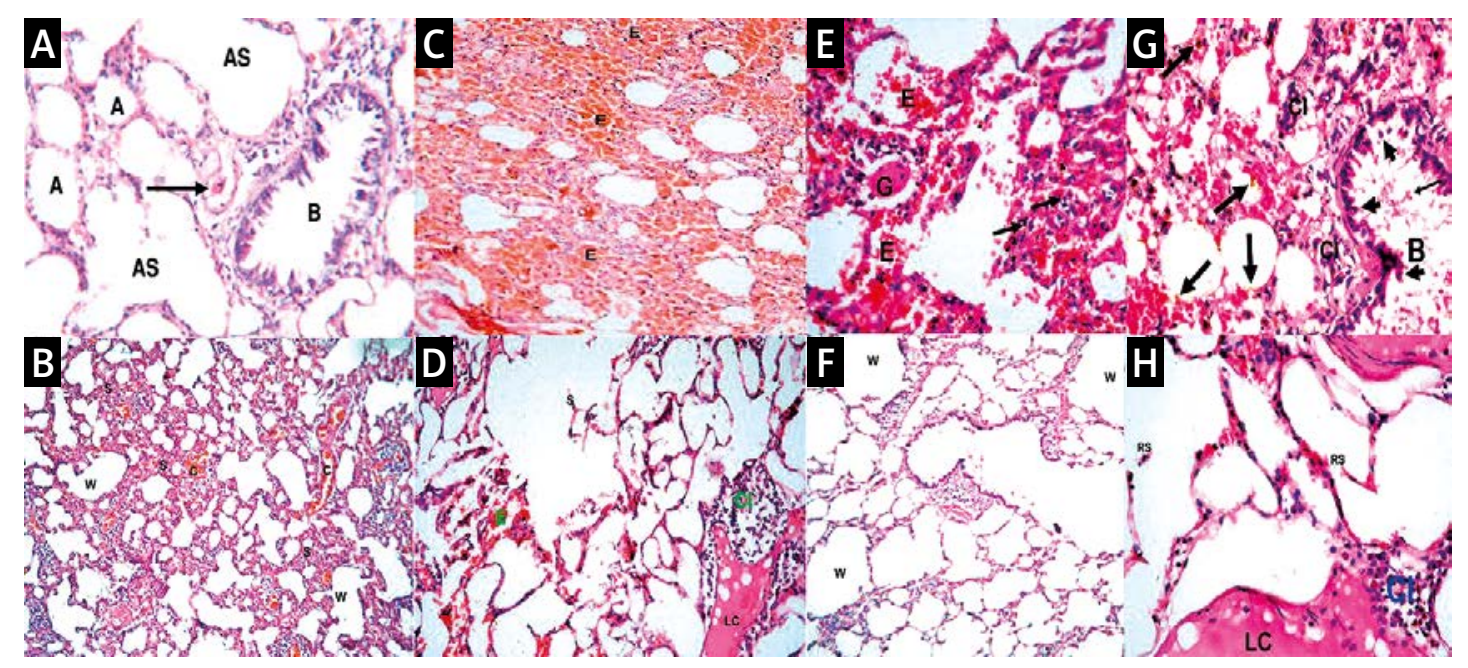

Figure 2. A - Normal alveoli (A), alveolar sac (AS), bronchiole (B) and blood vessel (arrow) in a control rat (H + E; 400x). B - Thickened septa (S), widened air spaces (W) and congested blood vessels (C) in a rat of group I ( $\mathrm{H}+$ E; 100x). C - Massive areas of blood extravasation (E) in the lung of a rat of group I (H + E; 200x). D - Lymphatic congestion (LC), ruptured septa $(\mathrm{S})$ with cellular infiltration $(\mathrm{Cl})$ and extravasation of blood $(\mathrm{E})$ in the lung of a rat of group I (H + E; 200x). E - Giant multi-nucleated cell (G), cellular infiltration (arrows) and areas of blood extravasation (E) in the lung of a rat of group I $(\mathrm{H}+\mathrm{E} ; 400 \times)$. F - Thin and ruptured septa with widened air spaces (W) in the lung of a rat of group II (H + E; 100x). G - Congested blood vessels (C), thickened septa (S), shredded cells (arrowheads), haemosiderin granules (thick arrows), cellular infiltration (CI) and secretions (thin arrow) in a respiratory bronchiole (B) in a rat of group II $(\mathrm{H}+\mathrm{E} ; 400 \times)$. $\mathrm{H}$ - Lymphatic congestion (LC), thin ruptured septa (RS) and cellular infiltration $(\mathrm{Cl})$ in a rat of group $\mathrm{II}(\mathrm{H}+\mathrm{E} ; 400 \times)$ 


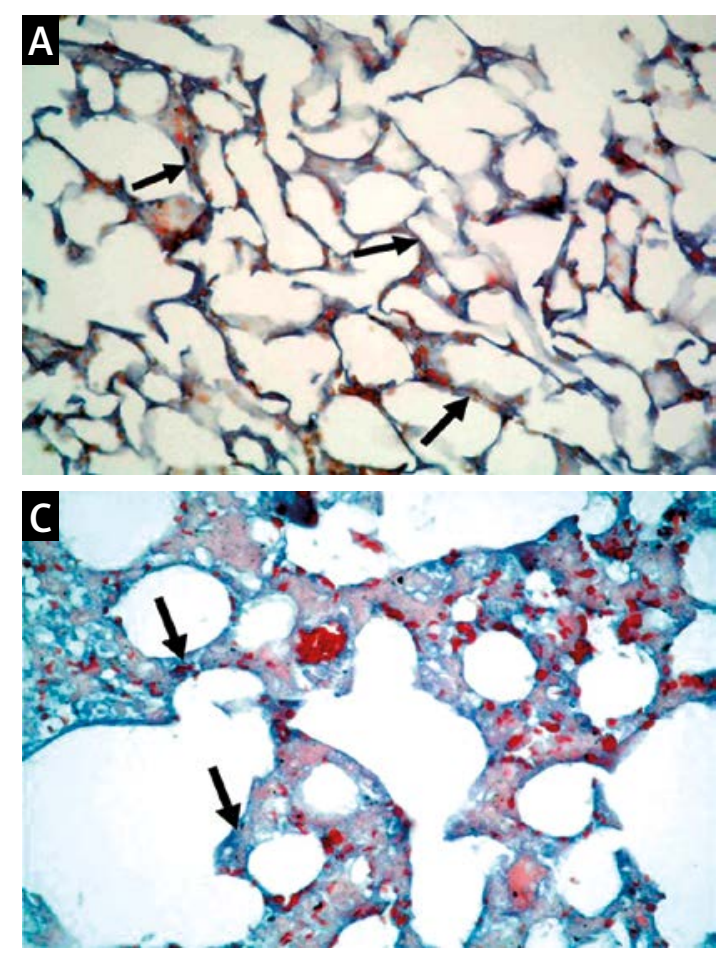

Morphometric results

There was a statistically significant increase in the mean percentage area of collagen, septal

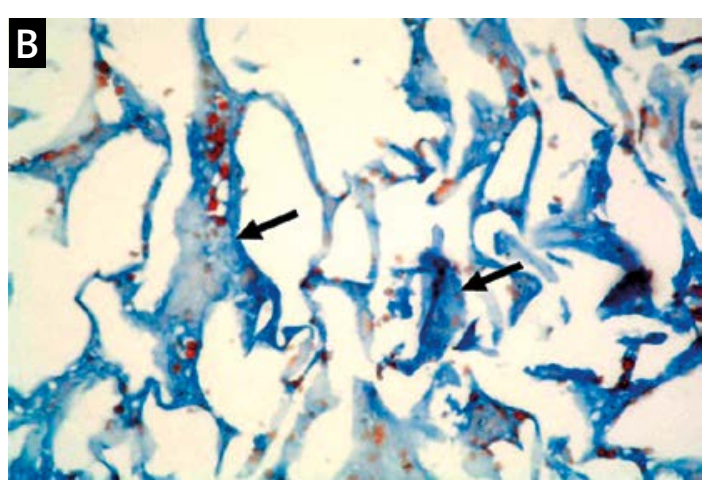

Figure 3. Connective tissue pattern (arrows) in the different groups (Masson's trichrome 400x). A - Control group, $\mathbf{B}$ - group I, C - group II

wall thickness, and number of macrophages in the chronic fluorosis group (group I) in comparison to the control group. Meanwhile, the percentage area

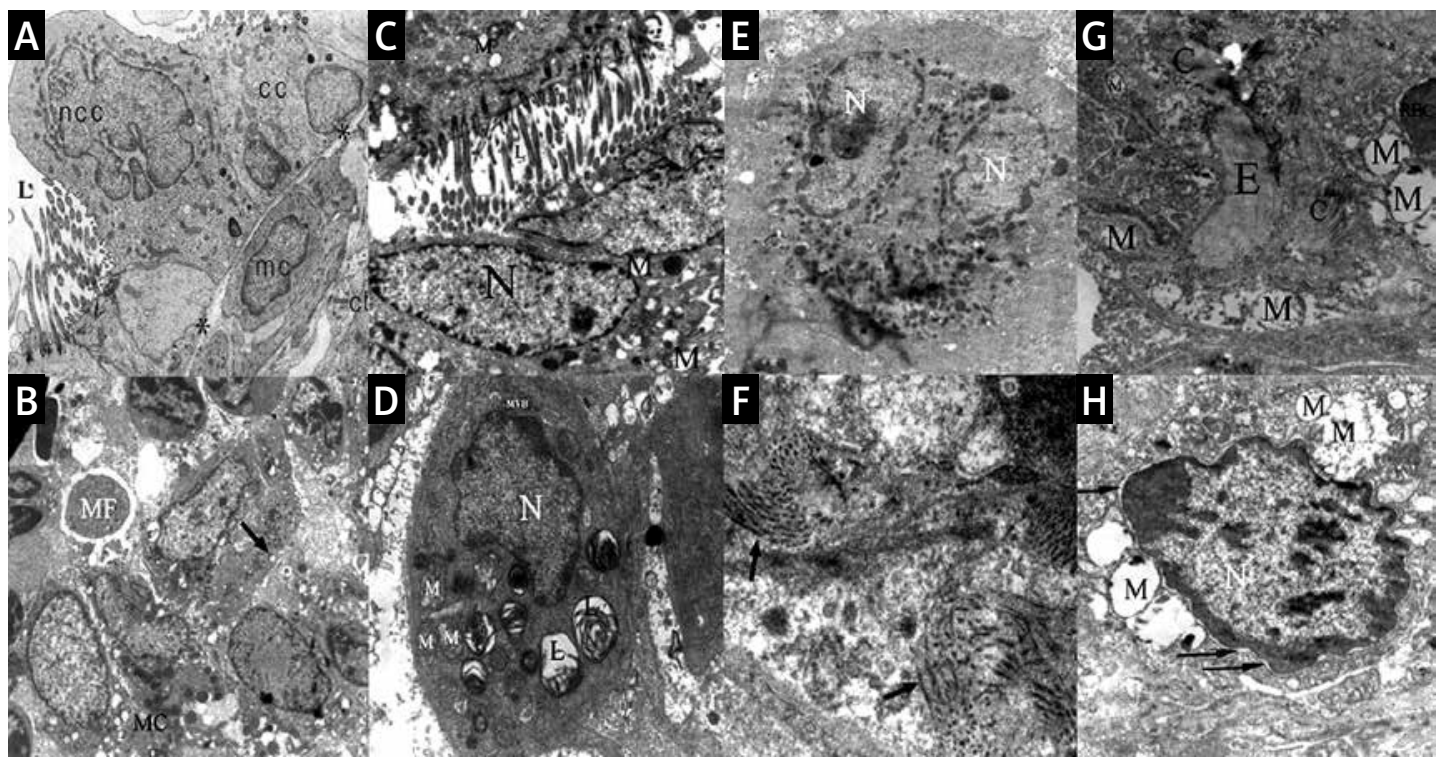

Figure 4. A - Non-ciliated Clara cell (ncc), ciliated epithelial cell (cc), basement membrane of the epithelium (*), smooth muscle cell $(\mathrm{mc})$, a fibroblast of connective tissue (ct) and the lumen (L) with cilia in both transverse and longitudinal sections in a control rat (6000x). B - Myelin figure (MF), Clara cell with glycogen particulates (arrow) and secretory granules in mucous cell (MC) in a bronchiole of a rat of group I (2500x). C - Collapsed lumen (L), disrupted cilia, swollen mitochondria $(M)$ with disrupted cristae and attenuated cytoplasm with presence of nuclei (N) near the lumen in a bronchiole of a rat of group I (6000x). D - Pneumocyte type II with lamellar bodies (L), marginated nucleus (N) with irregular nuclear membrane and mitochondria with lost cristae (M) (8000x) in a rat of group I. E - Binucleated (N) pneumocyte cell type I in a rat of group II (5000x). F - Abundant collagen fibres (arrows) in the alveolus interstitium of a rat of group II (20000x). G - Ballooned mitochondria (M) with rupture of cristae, homogeneous elastic fibres (E) and collagen fibres (C) in the alveolus interstitium of a rat of group II. Note red blood corpuscle (RBC) (12000x). H - Swollen mitochondria (M) with disrupted cristae, indented nucleus (N) with condensed marginated heterochromatin and widening of perinuclear space (arrows) in the alveolus interstitium of a rat of group II (12000x) 
Table I. Mean and SD of percentage area of collagen, septal wall thickness, number of macrophages and percentage area of air spaces of the different groups

\begin{tabular}{|lccccc|}
\hline Group & $\begin{array}{c}\text { Numbers of examined } \\
\text { preparations } \\
\text { in every group }\end{array}$ & $\begin{array}{c}\text { Area \% } \\
\text { of collagen, } \\
\text { mean } \pm \text { SD }\end{array}$ & $\begin{array}{c}\text { Septal wall } \\
\text { thickness, } \\
\text { mean } \pm \text { SD }\end{array}$ & $\begin{array}{c}\text { Macrophages } \\
\text { number, } \\
\text { mean } \pm \text { SD }\end{array}$ & $\begin{array}{c}\text { Area \% } \\
\text { of air spaces, } \\
\text { mean } \pm \text { SD }\end{array}$ \\
\hline Control & 40 & $0.28 \pm 0.35$ & $5.7 \pm 2.6$ & $1.2 \pm 1.2$ & $64.12 \pm 3.6$ \\
\hline I & 40 & $1.13 \pm 0.5$ & $13.47 \pm 6.1$ & $5 \pm 2.5$ & $51.34 \pm 10.6$ \\
\hline II & 40 & $0.25 \pm 0.17$ & $11.62 \pm 4.18$ & $1.4 \pm 0.97$ & $59.6 \pm 18.9$ \\
\hline
\end{tabular}

SD - standard deviation

of air spaces of this group was statistically significantly lower in comparison to the control group. With discontinuation of sodium exposure (group II), a statistically significant improvement of the percentage area of collagen, and the number of macrophages was noted. On the other hand, the septal wall thickness and the percentage area of air spaces showed no significant change compared to group I. Most of the parameters of group II were still different from the control group (Tables I and II).

\section{Discussion}

Fluoride is a potent enzyme poison. The chronic fluorosis group (group I) was characterized by the presence of marked pathological effects on the lung. This destructive effect might be attributed to the effect of lipid peroxidation [8]. The increase in the level of lipid peroxides is associated with the decrease in the activities of superoxide dismutase, catalase, and glutathione peroxidase [11]. Another possible explanation for the destructive effect of chronic fluorosis intoxication is the alteration of antioxidant status, which may increase generation of free radicals [11]. Such free radicals affect cellular components such as lipids, proteins, DNA and carbohydrates [8].

The presence of myelin figures in the chronic fluorosis group seemed to be due to conformational changes of membrane protein and lipoprotein layers [12], as fluorosis reduces membrane lipids, especially phospholipids $[3,13]$.

The presence of congested blood vessels, exudate and cellular infiltration in group I indicates the presence of inflammatory reactions which might be attributed to the release of IL- 6 and IL-8 from a human lung epithelial cell line [14]. Also, the increase of alveolar macrophages in this group mediates the observed pulmonary inflammation via the production of chemokines [15].

Emphysema and alveolar wall destruction in the chronic fluorosis group might be due to excess protease or elastase activity unopposed by appropriate antiprotease regulation with subsequent elastic tissue destruction and ruptured septal walls [16]. Also, matrix metalloproteinases derived
Table II. Comparison of mean \% area of collagen, septal wall thickness, number of macrophages and $\%$ area of air spaces of the different groups

\begin{tabular}{|c|c|c|c|}
\hline & Group & $\begin{array}{l}\text { Versus } \\
\text { group }\end{array}$ & $\begin{array}{l}\text { Value } \\
\text { of } p\end{array}$ \\
\hline \multirow{3}{*}{$\begin{array}{l}\text { Mean } \% \text { area } \\
\text { of collagen }\end{array}$} & Control & I & $0.001^{*}$ \\
\hline & & II & 0.7 \\
\hline & I & II & $0.001^{\star}$ \\
\hline \multirow{3}{*}{$\begin{array}{l}\text { Mean septal } \\
\text { wall thickness }\end{array}$} & Control & I & $0.001^{*}$ \\
\hline & & II & $0.001^{*}$ \\
\hline & I & II & 0.2 \\
\hline \multirow{3}{*}{$\begin{array}{l}\text { Macrophages } \\
\text { number }\end{array}$} & Control & I & $0.001^{\star}$ \\
\hline & & II & 0.6 \\
\hline & I & II & $0.006^{*}$ \\
\hline \multirow{3}{*}{$\begin{array}{l}\% \text { Area } \\
\text { of air spaces }\end{array}$} & Control & 1 & $0.002^{\star}$ \\
\hline & & II & 0.4 \\
\hline & I & II & 0.42 \\
\hline
\end{tabular}

*Statistically significant

from macrophages and neutrophils had a role in tissue destruction [16].

Capillary congestion in group I might be due to the previously mentioned inflammatory process or due to the chemical mediators released after tissue damage [17] with subsequent ruptures of the capillary and extravasation of the blood.

The mitochondrial effect in group I might be a sign of a degenerative effect as fluoride ions penetrated the mitochondria via simple diffusion [18]. The mitochondrial swelling observed in this group might be a manifestation of ATP deficiency [14].

The percentage area of fibrosis increased in group I. This fibrosis might be elastic or collagenous tissues as observed by using the TEM study. The collagen synthesis was probably induced by growth factors and cytokines secreted by leukocytes and fibroblasts [12]. Collagen deposition might also be associated with elastase-induced emphysema [19].

The main aim of the current work was to study the irreversible effect of sodium fluoride on lung 
tissue. This was done through studying the histological and morphometric changes after the discontinuation of sodium fluoride (the recovery group, group II). With discontinuation of sodium fluoride, not much improvement was observed and the same previous pathological findings persisted. Although the percentage area of collagen and the number of macrophages were significantly improved in this group, the septal wall thickness and the percentage area of air spaces showed no significant improvement. Most of the morphometric parameters were still different from the control group.

Proliferation of pneumocytes II was observed in group II as compensatory hyperplasia replacing the destroyed septal parts as pneumocyte II cells are known to retain the capacity for cell division and could differentiate into type I pneumocytes [13].

In conclusion, chronic fluorosis has many pathological effects on the lung. On both a histological and a morphometric basis, its effect on the lung tissue is irreversible. So, we recommend measurement of additional functional parameters and at least one or two oxidative markers (SOD, catalase activity, lipid peroxidation) in tissue samples after sodium fluoride exposure to support this conclusion. Also the evaluation of one/two lung inflammatory markers, such as TNF and IL-6, is very important to support this conclusion.

\section{References}

1. Stawiarska-Pieta B, Paszczela A, Grucka-Mamczar E, Szaflarska-Stojko E, Birkner E. The effect of antioxidative vitamins $A$ and $E$ and coenzyme $Q$ on the morphological picture of the lungs and pancreata of rats intoxicated with sodium fluoride. Food Chem Toxicol 2009; 47: 2544-50

2. Vasant RA, Khajuria MC, Narasimhacharya AV. Antioxidant and ACE enhancing potential of Pankajakasthuri in fluoride toxicity: an in vitro study on mammalian lungs. Toxicol Ind Health 2011; 27: 793-801.

3. Wang YN, Xiao KQ, Liu JL, Dallner G, Guan ZZ. Effect of long term fluoride exposure on lipid composition in rat liver. Toxicology 2000; 146: 161-9.

4. Zhavoronkov AA. Non-skeletal forms of fluorosis [Russian]. Arkh Patol 1977; 39: 83-91.

5. Denbesten P, Li W. Chronic fluoride toxicity: dental fluorosis. Monogr Oral Sci 2011; 22: 81-96.

6. Prado E, Wurtz T, Ferbus D, Shabana el-H, Forest N, Berdal A. Sodium fluoride influences the expression of keratins in cultured keratinocytes. Cell Biol Toxicol 2011; 27: 69-81.

7. Karaoz E, Oncu M, Gulle K, et al. Effect of chronic fluorosis on lipid peroxidation and histology of kidney tissues in first- and second-generation rats. Biol Trace Elem Res 2004; 102: 199-208.

8. Oncu M, Gulle K, Karaoz E, et al. Effect of chronic fluorosis on lipid peroxidation and histology of lung tissues in first and second generation rats. Toxicol Ind Health 2006; 22: 375-80.
9. Bancroft JD, Gamble M. Theory and practice of histological techniques. 5th ed., Churchill Livingstone, London 2002; 167-70.

10. Dykstra MJ, Reiss LE. Biological electron microscopy: theory, techniques, and troubleshooting. 2nd ed. Library of congress, New York 2003; 75-100.

11. Shanthakumari D, Srinivasalu S, Subramanian S. Effect of fluoride intoxication on lipidperoxidation and antioxidant status in experimental rats. Toxicology 2004; 204: 219-28.

12. Castejón OJ, Arismendi GJ. Nerve cell death types in the edematous human cerebral cortex. J Submicrosc Cytol Pathol 2006; 38: 21-36.

13. Sindelar PJ, Guan Z, Dallner G, Ernster L. The protective role of plasmalogens in iron-induced lipid peroxidation. Free Radic Biol Med 1999; 26: 318-24.

14. Refsnes $M$, Becher R, Lâg $M$, Skuland T, Schwarze PE. Fluoride-induced interleukin-6 and interleukin-8 synthesis in human epithelial lung cells. Hum Exp Toxicol 1999; 18: 645-52.

15. Chong IW, Lin SR, Hwang JJ, et al. Expression and regulation of the macrophage inflammatory protein-1 alpha gene by nicotine in rat alveolar macrophages. Eur Cytokine Netw 2002; 13: 242-9.

16. Kumar KM, Abba AK, Fausto N. Cellular interactions in pulmonary fibrosis. Robbins and Cotran pathological basis of disease. 7th ed. Library of Congress, Philadelphia 2004; 27-118.

17. Wheater P, Burkitt G, Stevens A, Lowe J. Cellular response to injury. In: Basic histopathology. 2nd ed. Churchill Livingstone, Hong Kong 1990; 220-34.

18. Dabrowska E, Balunowska M, Letko R, Szynaka B. Ultrastructural study of the mitochondria in the submandibular gland, the pancreas and the liver of young rats, exposed to NaF in drinking water. Rocz Akad Med Bialymst 2004; 49 Suppl. 1: 180-1.

19. Chabre M. Aluminofluoride and beryllofluoride complexes: a new phosphate analogs in enzymology. Trends Biochem Sci 1990; 15: 6-10. 